\title{
Changbaishan volcanism in northeast China linked to subduction-induced mantle upwelling
}

\author{
Youcai Tang ${ }^{1,2}$, Masayuki Obayashi ${ }^{3}$, Fenglin Niu ${ }^{1,4 \star}$, Stephen P. Grand ${ }^{2}$, Yongshun John Chen ${ }^{5}$, \\ Hitoshi Kawakatsu ${ }^{6}$, Satoru Tanaka ${ }^{3}$, Jieyuan Ning ${ }^{5}$ and James F. $\mathrm{Ni}^{7}$
}

\begin{abstract}
Volcanism that occurs far from plate margins is difficult to explain with the current paradigm of plate tectonics. The Changbaishan volcanic complex, located on the border between China and North Korea, lies approximately 1,300 km away from the Japan Trench subduction zone and is unlikely to result from a mantle plume rising from a thermal boundary layer at the base of the mantle. Here we use seismic images and three-dimensional waveform modelling results obtained from the NECESSArray experiment to identify a slow, continuous seismic anomaly in the mantle beneath Changbaishan. The anomaly extends from just below $660 \mathrm{~km}$ depth to the surface beneath Changbaishan and occurs within a gap in the stagnant subducted Pacific Plate. We propose that the anomaly represents hot and buoyant sub-lithospheric mantle that has been entrained beneath the sinking lithosphere of the Pacific Plate and is now escaping through a gap in the subducting slab. We suggest that this subduction-induced upwelling process produces decompression melting that feeds the Changbaishan volcanoes. Subductioninduced upwelling may also explain back-arc volcanism observed at other subduction zones.
\end{abstract}

M ost magmatism on Earth occurs on plate boundaries and is well explained by plate tectonics. However, there are many intraplate locations of volcanic activity as well. Some intraplate volcanism has been postulated to be due to deep mantle plumes, such as Hawaii, but it is unlikely that all intraplate volcanism is related to this phenomenon. Late Cenozoic intraplate volcanism is widespread in northeast China. The largest active magmatic centre in northeast China is in the Changbaishan (also known as Baitoushan) volcanic region located on the border between China and North Korea (Fig. 1). The magmatism occurs within a broad topographic high that has a diameter of about $300 \mathrm{~km}$ and a maximum elevation of near $2,800 \mathrm{~m}$. It is composed of several active volcanoes that have erupted several times during the past 2,000 years including one of the largest eruptions in recorded history about 1,000 years ago ${ }^{1}$. This intraplate volcanic centre is far from the Japan Trench where the Pacific Plate starts to penetrate into the mantle beneath Japan and is difficult to explain using the plate tectonic paradigm. A deep mantle plume rooted in the base of the lower mantle is an unlikely source for Changbaishan because there is no slow seismic anomaly in the lower mantle indicative of mantle upwelling $^{2}$, there is no evidence for a flood basalt indicating the arrival of a plume head, the total volume of the erupted basalts is relatively small compared with other proposed deep plumes, and, finally, there is no 'hotspot' track associated with the volcanism.

Mantle upwelling and decompression melting at shallow depths has previously been invoked to explain Cenozoic magmatism in northeast $\mathrm{China}^{3-5}$. A large-scale asthenospheric upwelling has also been suggested to associate with the opening of the Japan Sea and overall extension in northeast $\mathrm{China}^{6}$. However, the origin and dynamics of mantle upwelling has remained controversial.
The westward subducting Pacific slab approaches the eastern edge of northeast China at about $600 \mathrm{~km}$ depth (Fig. 1). Previous tomography models show that a stagnant slab exists in the transition zone beneath northeast China ${ }^{4,7,8}$. On the basis of these results, several studies propose that Changbaishan volcanism is associated with the dehydration of the stagnant slab in the transition zone beneath northeast China ${ }^{4,9}$ and upwelling of hydrated mantle from the top of the flat slab. However, some studies suggest that the intraplate magmatism was probably not affected by fluids derived from the stagnant slab, on the basis of the absence of any islandarc geochemical signature in the erupted rocks ${ }^{3,10}$. It has been suggested that piling up and thickening of stagnant slab in the transition zone can drive upwelling of normal asthenosphere and induce decompression melting at shallow depth ${ }^{3}$. Although these studies present conceptual models for Changbaishan volcanism they do not address specifically why the volcanism is focused under one region and not distributed along strike of the subduction zone. Geodynamic studies indicate an alternative model showing that focused mantle upwelling can be generated both ahead of deep subducting slab and around the lateral edges of slab and produce decompression melting at shallow depths ${ }^{11}$ associated with subduction zones, although far from arcs. This mechanism is most viable during the initial phase of slab descent.

\section{Seismic images and waveform modelling}

Here we present new seismic images of the mantle beneath northeast China that show that Changbaishan is fed by a subduction-induced upwelling originating from depths near $700 \mathrm{~km}$. The analyses used data recorded by the northeast China Extended SeiSmic Array (NECESSArray; Fig. 1), which is a multi-national collaborative

\footnotetext{
${ }^{1}$ State Key Laboratory of Petroleum Resource and Prospecting, and Unconventional Natural Gas Institute, China University of Petroleum, Beijing 102249, China, ${ }^{2}$ Jackson School of Geosciences, The University of Texas at Austin, Austin, Texas 78712, USA, ${ }^{3}$ Institute for Research on Earth Evolution, Japan Agency for Marine-Earth Science and Technology, 2-15 Natsushima-cho, Yokosuka-city, Kanagawa 237-0061, Japan, ${ }^{4}$ Department of Earth Science, MS-126, Rice University, Houston, Texas 77005, USA, ${ }^{5}$ Institute of Theoretical and Applied Geophysics, SESS, Peking University, Beijing 100871, China, ${ }^{6}$ Earthquake Research Institute, the University of Tokyo, Tokyo 113-0032, Japan, ${ }^{7}$ Department of Physics, New Mexico State University, Las Cruces, New Mexico 88003-8001, USA. *e-mail: niu@rice.edu
} 


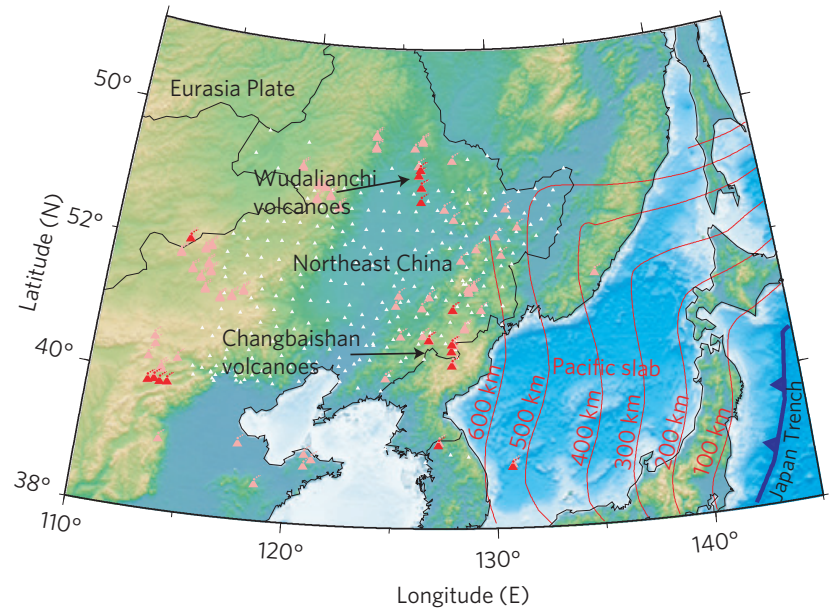

Figure 1 | Map of northeast China and surrounding areas. White triangles indicate the NECESSArray stations, which consists of 127 temporary and 140 permanent broadband stations operated by the China Earthquake Administration. The temporary stations were deployed under an international collaboration between September 2009 and August 2011. Red and pink triangles are Holocene and Cenozoic volcanoes in northeast China, respectively. Changbaishan is the largest active magmatic centre in China. Red lines indicate the Wadati-Benioff zone, showing the geographic location of the subducting Pacific slab at different depths. Note that Changbaishan is located far from the Japan Trench, but sits at a location where the subducted Pacific slab reaches $\sim 660 \mathrm{~km}$ depth.

seismic experiment that deployed 127 broadband seismometers across northeast China and also includes $\sim 140$ seismometers from the China Earthquake Administration. P and S tomography images, discussed in detail in the Supplementary Methods, show fast seismic velocities from 600 to $700 \mathrm{~km}$ depth along the eastern edge of northeast China (Fig. 2). The high velocities are at the western edge of an extension of the Wadati-Benioff zone and are due to stagnating Pacific slab that spreads laterally (to the west) for 300 to $500 \mathrm{~km}$ near $600 \mathrm{~km}$ depth. Stagnant slabs have been reported in previous tomography studies ${ }^{4,7,8}$ as well. However, in the middle of the deep high-velocity slabs, a slow cylindrical anomaly is observed near $\left(43^{\circ} \mathrm{N} 124^{\circ} \mathrm{E}\right)$ that appears as a hole within the stagnant slab (circled in green in Fig. 2). A similar gap between stagnant slabs is apparent in previous $\mathrm{P}$-wave tomography models ${ }^{8}$. The slow anomaly can be followed from depth to near the surface with an eastward tilt where extremely slow velocities are found beneath Changbaishan from 100 to $200 \mathrm{~km}$ depth. The slow cylindrical anomaly is best seen in cross-section (Fig. 3). Receiver-function analysis was used to map the depths of the 410 and $660 \mathrm{~km}$ discontinuities (Supplementary Fig. 4). A strong depression of the $660 \mathrm{~km}$ discontinuity $(25-40 \mathrm{~km})$ is correlated with the high-velocity stagnant slab but an uplift of the discontinuity of $6-12 \mathrm{~km}$ is observed at the location of the slow anomaly.

To further constrain the seismic characteristics of the slow cylindrical anomaly observed in the tomography results, we examined the horizontally polarized ( $\mathrm{SH}$ ) displacement waveforms across the NECESSArray for waves that propagated through the transition zone anomaly. We observed strong waveform distortions from several earthquakes located to the south of the array. For each earthquake, there exists a cluster of stations whose S-wave amplitude is substantially higher than the other stations (Fig. 4). Also, at the stations near the edges of the cluster the recorded SH waves are more complex than other stations, usually appearing as two small-amplitude pulses. The location of the high-amplitude station clusters changes with event location such that the amplitude anomalies are clearly associated with the low-velocity anomaly. We used the spectral-element method (SPECFEM3D; ref. 12) to construct three-dimensional synthetic waveforms using our tomographic S-model and found a similar pattern to the observed waveform distortions but with no double pulses (Supplementary Figs 5 and 6). Synthetic tests for the S-wave tomography inversion indicate that amplitude is not well recovered at transition zone depths (Supplementary Fig. 2) so we doubled the transition zone anomalies (below $400 \mathrm{~km}$ depth) in the S-model and obtain a much better match to the observed waveforms (Fig. 4 and Supplementary Figs 5 and 6). We conclude that the $S$ velocity contrast between the slow anomaly within the slab gap and the surrounding slabs is $\sim 8 \%$.

\section{Subduction-induced upwelling}

We propose a new model for generating volcanism in the Changbaishan region (Fig. 5) based on our new seismic observations. The slow cylindrical velocity anomaly from $700 \mathrm{~km}$ depth to below Changbaishan is a manifestation of mantle upwelling that results in decompression melting producing the observed magmatism in the region. The upwelling rises through a gap in the deep stagnant slabs beneath northeast China. The gap may exist owing to sinking of a portion of the stagnant slab into the lower mantle in the past or perhaps to the Pacific slab rifting at depth into a northern and southern segment. Slab retreat and normal mantle wedge flow tilt the upwelling eastward as it rises.

An important question is whether the slow anomaly is hot, and thus superadiabatic or just represents return flow of average temperature mantle. The large velocity contrast revealed by waveform modelling is unlikely to be the velocity contrast between the slab and normal transition zone mantle because if this were the case, a travel time misfit with observed data to the west would result. Thus, the slow transition zone anomaly within the slab gap has lower shear velocity than what is probably normal transition zone mantle. We further note that the $660-\mathrm{km}$ discontinuity is shallower where the anomaly is located than to the west (Fig. 3 and Supplementary Fig. 4). Estimates of the Clapeyron slope of the ringwoodite-to-perovskite phase transition, corresponding to the $660-\mathrm{km}$ discontinuity, range from $-2.8 \mathrm{MPa} \mathrm{K}^{-1}$ (refs 13,14) to $-1.3 \mathrm{MPa} \mathrm{K}^{-1}$ (ref. 15). Assuming a value of $-2.0 \mathrm{MPa} \mathrm{K}^{-1}$ (ref. 16), the observed 6-12 km uplift corresponds to a $120-240 \mathrm{~K}$ temperature anomaly. The $\sim 8 \%$ velocity contrast between the slow anomaly and its surrounding slabs in the transition zone corresponds to a $\sim 800 \mathrm{~K}$ temperature difference if we use $-1.0 \times 10^{-4} \mathrm{~K}^{-1}$ as the temperature dependence of shear wave velocity ${ }^{17}$. The calculated temperature profile of the subducting slab beneath Japan Trench indicates that the temperature difference between the slab and surrounding mantle in the transition zone is around $650 \mathrm{~K}$ (ref. 18). If we assume a relative decrease of $650 \mathrm{~K}$ within the stagnant slab, then the slow anomaly inside the slab gap will be $\sim 150 \mathrm{~K}$ higher in temperature than normal transition zone mantle to the west, which is consistent with the value estimated from the receiver-function results. The $650 \mathrm{~K}$ low-temperature anomaly in the slab would cause a $\sim 32 \mathrm{~km}$ depression of the $660-\mathrm{km}$ discontinuity. Part of the depression of the $660-\mathrm{km}$ discontinuity revealed by receiver-function analysis (a maximum of $40 \mathrm{~km}$, which occurs at the location where the subducted slab first reaches $660-\mathrm{km}$ depth) may be caused by a kinetic delay in the phase transition for slab material that has penetrated into the lower mantle $e^{18,19}$

As discussed previously, it is unlikely a deep mantle plume exists beneath northeast China. $\mathrm{P}$ wave tomography and waveform modelling results ${ }^{20}$ show anomalously hot $(200 \mathrm{~K}$ excess temperature) mantle on the oceanward side of the subducting Pacific Plate near Japan centred at $400 \mathrm{~km}$ depth. A recent study using reflected shear waves between the Earth's surface and the core-mantle boundary ${ }^{21}$ found evidence of a $150{ }^{\circ} \mathrm{C}$ hightemperature anomaly at $350 \mathrm{~km}$ depth oceanward of the Honshu slab. Geodynamic calculations ${ }^{22,23}$ show that anomalously hot, 
a

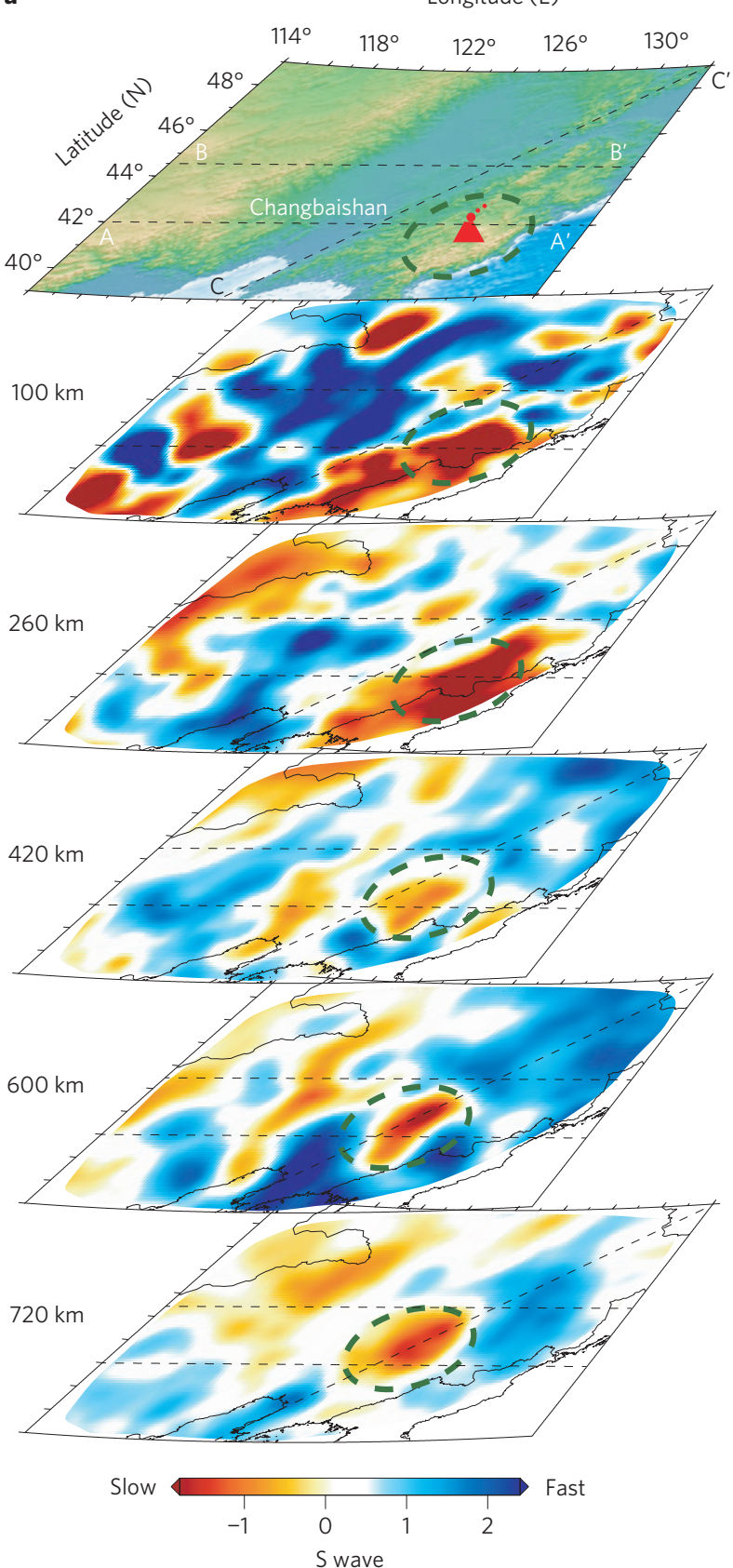

b

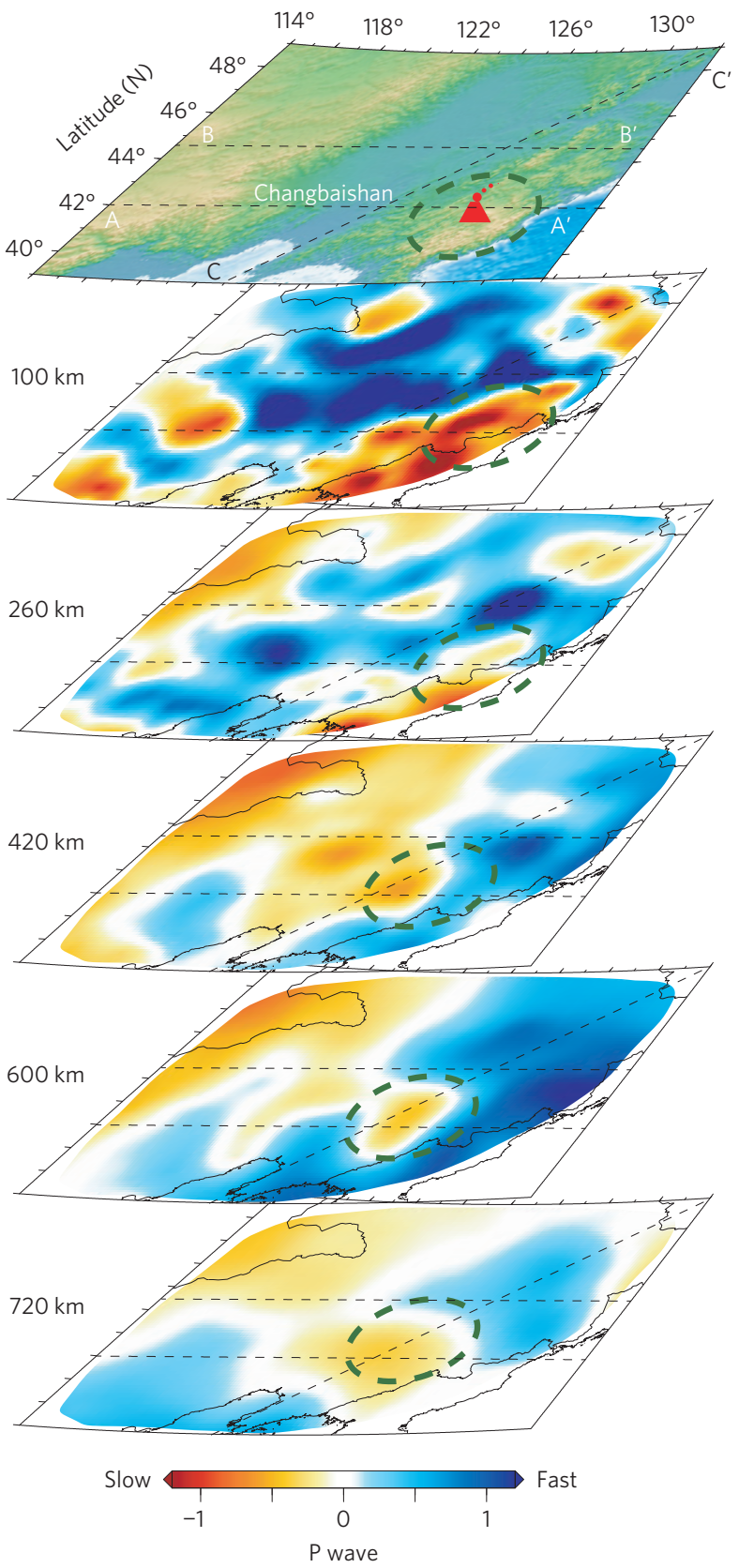

Figure $\mathbf{2}$ | Tomographic images beneath northeast China. a,b, The NECESS S (a) and P (b) models. Fast and slow anomalies are indicated by blue and red colours, respectively. For each column, a topographic map is shown at the top with different depth slices below. The red volcanic symbol represents the Changbaishan volcanic complex, and the black dashed lines show the locations of three profiles along latitudes $42^{\circ} \mathrm{N}\left(A-A^{\prime}\right), 44.5^{\circ} \mathrm{N}\left(B-B^{\prime}\right)$, and a southwest-northeast section ( $\left.C-C^{\prime}\right)$ shown in Fig. 3. The dashed green circle on each map shows the low-velocity conduit that extends from the transition zone to the surface with a gentle eastward tilt.

buoyant asthenosphere will be dragged downward by subducting lithosphere to depths exceeding $660 \mathrm{~km}$ depth. A sharp lithosphereasthenosphere boundary beneath the Pacific Ocean offshore Japan has been inferred from receiver-function data ${ }^{24}$, which may suggest anomalously warm asthenosphere beneath the Pacific Plate. The sharp velocity drop at the bottom of the lithosphere has been interpreted as partially molten asthenosphere, which is in agreement with observations of a warm asthenosphere as the magmatic source of outer rise volcanoes (petit spots) offshore Japan ${ }^{25}$. The hot asthenospheric mantle beneath the western Pacific may have been delivered by active upwellings to the southeast, where large plumes have been seismically imaged in the lower mantle ${ }^{2}$, and flowed with the lithosphere towards Japan. Asthenosphere flow parallel to the direction of subducting lithosphere has been inferred from the observed seismic anisotropy ${ }^{26}$ and confirmed by numerical simulations $\mathrm{s}^{22,23}$. We propose that buoyant warm material is carried beneath the subducting slab to the transition zone until an opening occurs where the buoyant material can rise (Fig. 5).

\section{New mechanism for the Changbaishan volcanism}

Although not conclusive, geochemical studies from alkaline basalts and xenoliths associated with Changbaishan magmatism are consistent with our model. An EM1 (Enriched Mantle 1) isotopic signature in basalts from the Changbaishan region has 
a

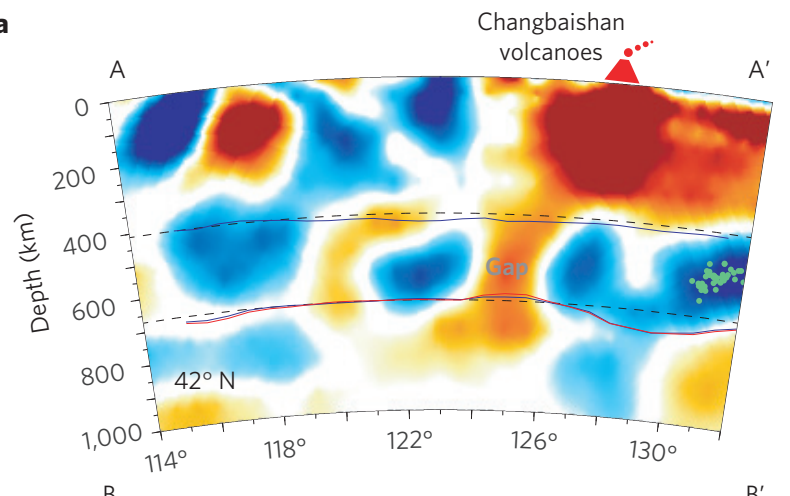

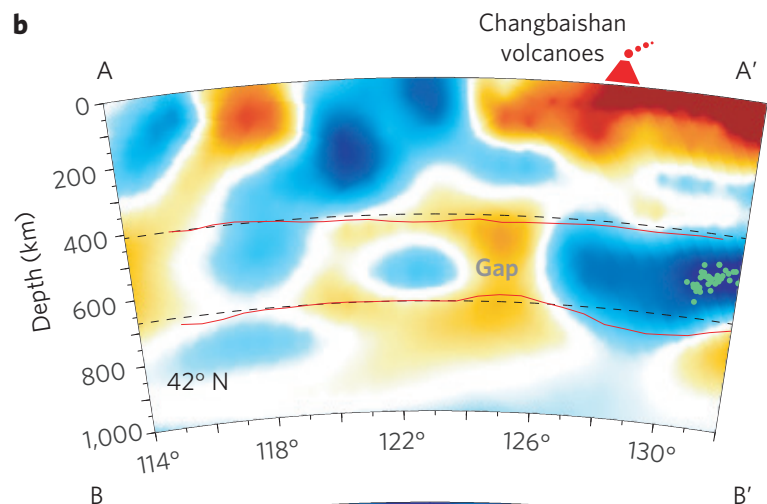
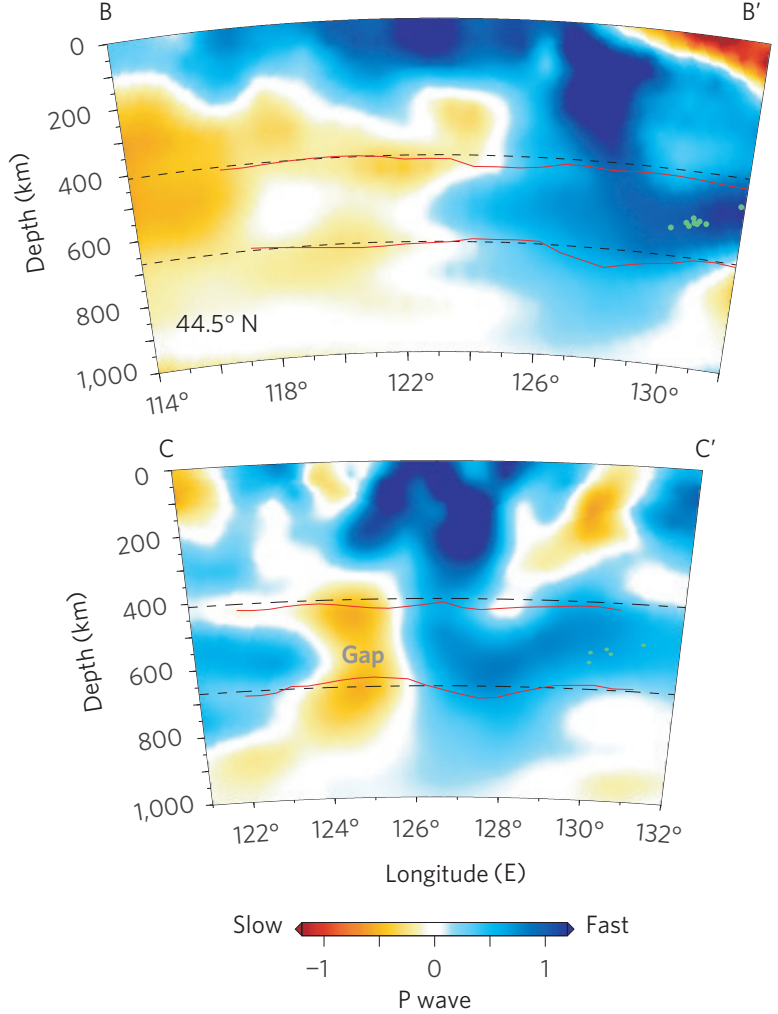

Figure 3 | Depth cross-sections of velocity anomalies. a,b, The NECESS S and P models along lines A- $A^{\prime}\left(42^{\circ} N\right.$, top), B- $B^{\prime}\left(44.5^{\circ} \mathrm{N}\right.$, middle) and C-C' (bottom). Fast and slow anomalies are indicated by blue and red colours, respectively. Green dots indicate deep earthquakes from 1973 to 2012 . Black dashed lines are at $410 \mathrm{~km}$ and $660 \mathrm{~km}$ depth. Red lines show the depth variations of the two discontinuities from receiver-function data using the NECESS $\mathrm{P}$ and $\mathrm{S}$ models with doubled anomaly amplitude in the transition zone for time-depth mapping. Note the good correlation between perturbations in seismic velocity and undulations of the 660-km discontinuity, as discussed in the text.

been suggested to originate from the transition zone that was metasomatized by subducted slab more than 1 Gyr ago ${ }^{9}$. Sources for EM1 isotopic signature magmas require at least 1 Gyr of isolation and are often associated with hotspots including Hawaii ${ }^{27}$. The petit spot volcanism offshore Japan has also been found to have a strong EM1 signature ${ }^{28}$. Although not proof, the strong EM1 isotopic signature in petit spot volcanic rocks offshore Japan and in Changbaishan magmas are consistent with both regions sampling asthenosphere that was contaminated by plumes beneath the Pacific and then transported under the Pacific Plate to the west. In addition, the Changbaishan and petit spot volcanic rocks also show similar distributions in trace element concentration (no depletion of $\mathrm{Nb}$ and $\mathrm{Ta}$ ), which are different from those of island-arc and mid-oceanic ridge basalts ${ }^{10,25}$.

Mantle upwellings could also be generated by return flow even without superadiabatic temperatures. When slabs descend into the lower mantle an associated mass-conserving counter flow drives an upwelling of the mantle into the region above the slab resulting in an upwelling through the upper mantle $e^{29,30}$. Numerical modelling shows that this focused upwelling probably occurs both at the leading and truncated edges of descending slabs ${ }^{11}$. Fragmented slabs at depth causing mantle upwelling and widespread basaltic magmatism have been proposed to occur beneath Yellowstone ${ }^{31}$. A similar process has also been proposed to take place at shallower depths in subduction zones ${ }^{32}$. Such a process may be the cause of the active Wudalianchi magmatism to the northwest of Changbaishan, which is near the northern edge of a flat slab.

We propose that the intraplate alkaline volcanism and topography swell associated with the Changbaishan volcanic region is fed by a mantle upwelling originating from below the $660-\mathrm{km}$ discontinuity. The upwelling is a result of a gap between stagnant slabs in the transition zone that allows return flow, including superadiabatic asthenosphere, to rise. Although similar subduction-related scenarios have been proposed to explain northeast China magmatism, our model differs from them in important aspects. Models that propose upwelling from the top 


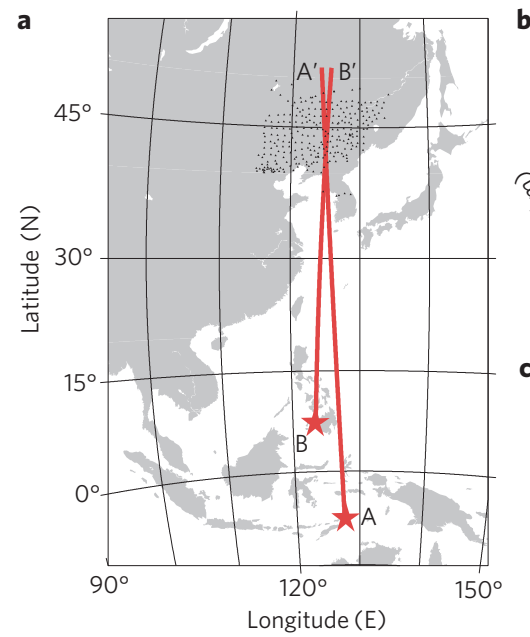

\section{b}

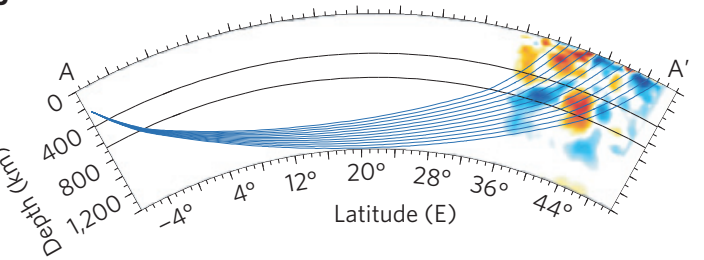

c

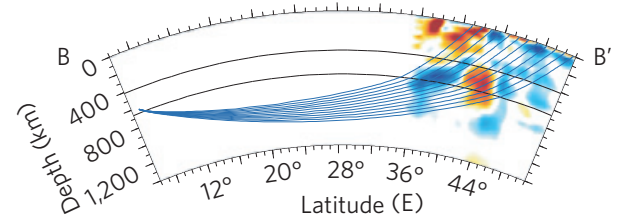

d
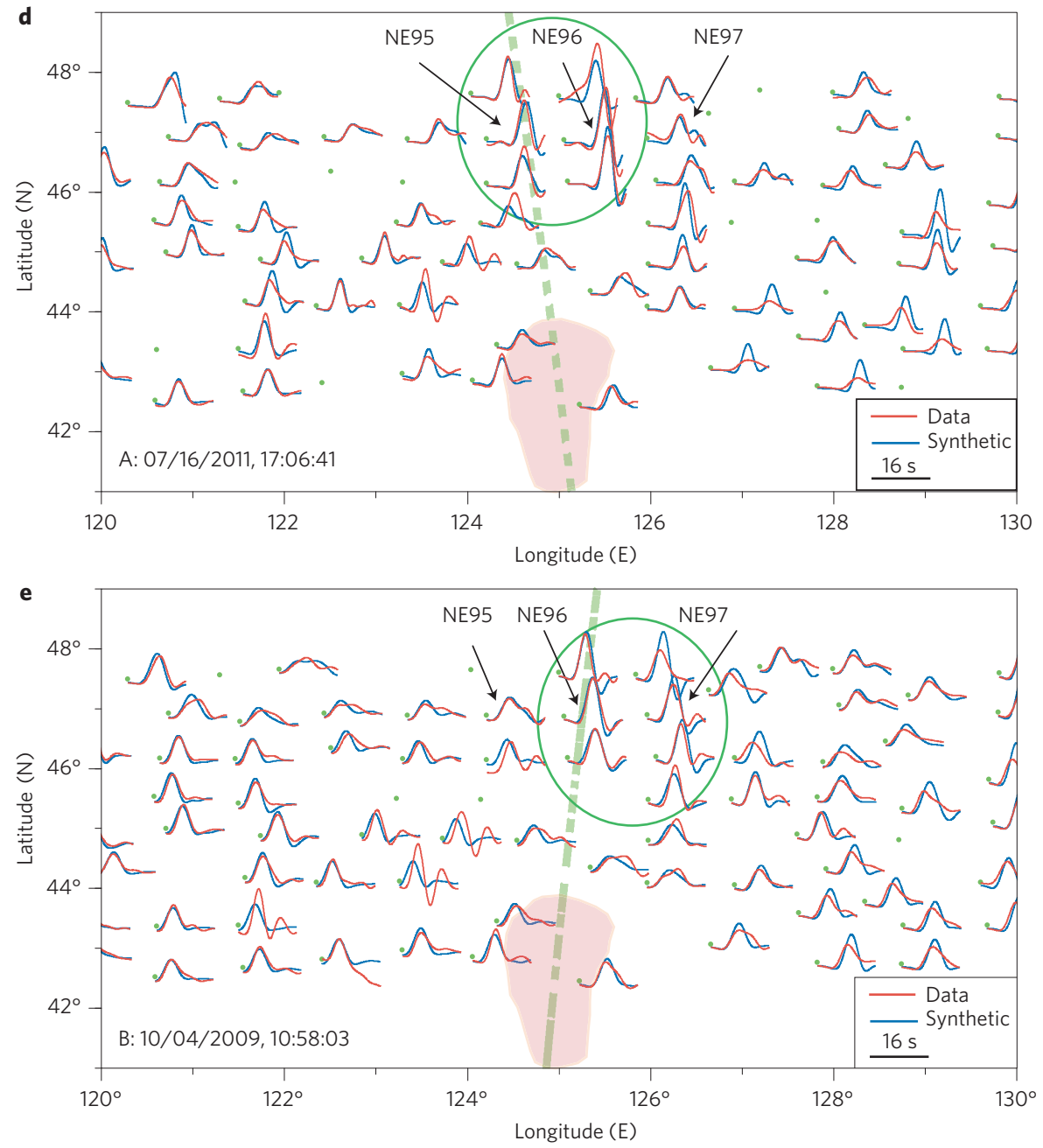

Figure 4 | Three-dimensional waveform modelling. a, Raypaths from two earthquakes used in waveform modelling that sample the transition-zone slow anomaly. Stars and dots indicate the two earthquakes and the NECESSArray stations, respectively. The two red lines represent the raypaths of stations showing anomalously high S-wave amplitudes. b,c, Depth sections of the S-wave raypaths to the stations along the two profiles with the NECESS S model. d,e, SH waveforms of the two earthquakes. Green ovals mark the stations with simple waveforms but large amplitudes, in comparison with those recorded to the east and west that are marked by complicated waveforms with smaller amplitude. The green dashed line corresponds to the two profiles shown in $\mathbf{a}$. The pink region denotes the location of the transition-zone slow anomaly.

of a flat slab in northeast China $^{4}$ do not explain the variation in magmatism along the north-south strike of the deep WadatiBenioff zone (Fig. 1) in northeast China nor the difference in shallow upper mantle velocities observed from north to south
(Fig. 3). Models that show return flow from initial impingement of slab into the lower mantle ${ }^{11}$ do not explain long-term magmatism in a well-established deep subduction environment such as the case in northeast China nor the rise of superadiabatic mantle. Our 


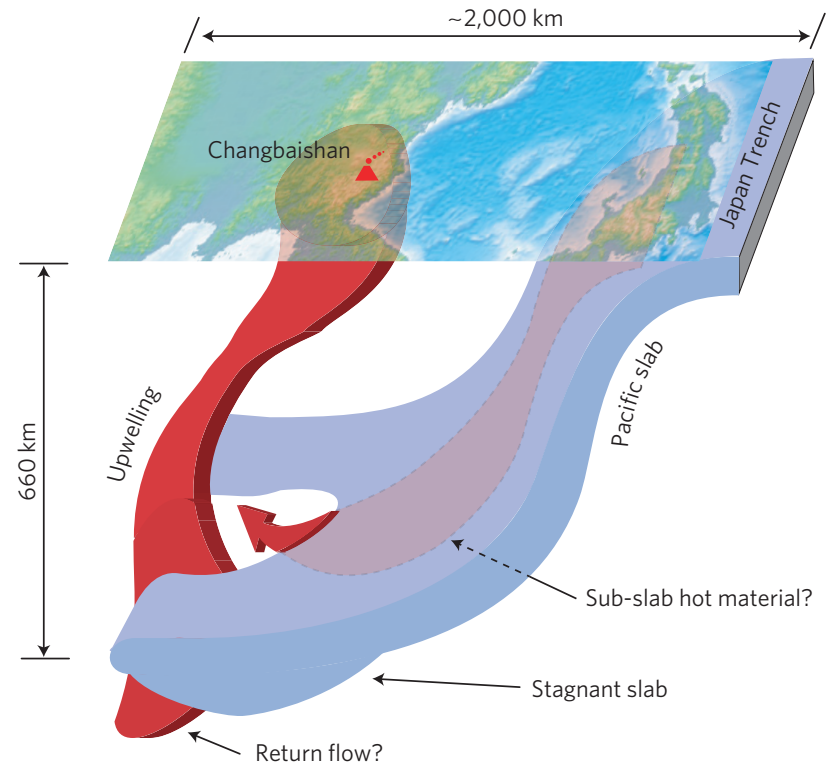

Figure 5 | Diagram showing our proposed model for the origin of Changbaishan volcanism. The subducting Pacific slab and the mantle upwelling are shown in blue and red, respectively. Exaggerated topography is shown at the top of the figure. The model has deep mantle upwelling that originates below the 660-km discontinuity, goes through a gap between slabs in the transition zone, and undergoes decompression melting at asthenosphere depths, which finally feeds the Changbaishan volcanism. The hot upwelling is return flow from slab entering the lower mantle, and is probably derived from hot sub-lithospheric mantle (shaded red below the slab) that was entrained beneath the sinking lithosphere.

model relies on a gap opening within subducting slab at depth to allow for a focused upwelling. The cause of the gap is still uncertain but may depend on local sinking of stagnant slab at the base of the upper mantle or the dynamics of slab descent through the transition zone.

Received 15 November 2013; accepted 11 April 2014; published online 18 May 2014

\section{References}

1. Wei, H. et al. Three active volcanoes in China and their hazards. J. Asian Earth Sci. 21, 515-526 (2003).

2. Montelli, R. et al. Finite-frequency tomography reveals a variety of plumes in the mantle. Science 303, 338-343 (2004).

3. Zou, H., Fan, Q. \& Yao, Y. U-Th systematics of dispersed young volcanoes in NE China: Asthenosphere upwelling caused by piling up and upward thickening of stagnant Pacific slab. Chem. Geol. 255, 134-142 (2008).

4. Zhao, D., Tian, Y., Lei, J., Liu, L. \& Zheng, S. Seismic image and origin of the Changbai intraplate volcano in East Asia: Role of big mantle wedge above the stagnant Pacific slab. Phys. Earth Planet. Inter. 173, 197-206 (2009).

5. Xu, Y-G., Zhang, H-H., Qiu, H-N., Ge, W-C. \& Wu, F-Y. Oceanic crust components in continental basalts from Shuangliao, Northeast China: Derived from the mantle transition zone? Chem. Geol. 328, 168-184 (2012).

6. Tatsumi, Y., Maruyama, S. \& Nohda, S. Mechanism of backarc opening in the Japan Sea: Role of asthenospheric injection. Tectonophysics 181, 299-306 (1990).

7. Fukao, Y., Obayashi, M., Nakakuki, T. \& Group, D. S. P. Stagnant slab: A review. Annu. Rev. Earth Planet. Sci. 37, 19-46 (2009).

8. Li, C. \& van der Hilst, R.D. Structure of the upper mantle and transition zone beneath Southeast Asia from traveltime tomography. J. Geophys. Res. 115, B07308 (2010).

9. Kuritani, T., Ohtani, E. \& Kimura, J-I. Intensive hydration of the mantle transition zone beneath China caused by ancient slab stagnation. Nature Geosci. 4, 713-716 (2011).
10. Chen, Y., Zhang, Y., Graham, D., Su, S. \& Deng, J. Geochemistry of Cenozoic basalts and mantle xenoliths in Northeast China. Lithos 96, 108-126 (2007).

11. Faccenna, C. et al. Subduction-triggered magmatic pulses: A new class of plumes? Earth Planet. Sci. Lett. 299, 54-68 (2010).

12. Tromp, J., Tape, C. \& Liu, Q-Y. Seismic tomography, adjoint methods, time reversal and banana-doughnut kernels. Geophys. J. Int. 160, 195-216 (2005).

13. Ito, E. \& Takahashi, E. Postspinel transformations in the system $\mathrm{Mg}_{2} \mathrm{SiO}_{4}-\mathrm{Fe}_{2} \mathrm{SiO}_{4}$ and some geophysical implications. J. Geophys. Res. 94, 10637-10646 (1989).

14. Hirose, K. Phase transitions in pyrolitic mantle around $670-\mathrm{km}$ depth: Implications for upwelling of plumes from the lower mantle. J. Geophys. Res. 107, 2078 (2002).

15. Fei, Y. et al. Experimentally determined postspinel transformation boundary in $\mathrm{Mg}_{2} \mathrm{SiO}_{4}$ using $\mathrm{MgO}$ as an internal pressure standard and its geophysical implications. J. Geophys. Res. 109, B02305 (2004).

16. Litasov, K. D., Ohtani, E. \& Sano, A. in In Earth's Deep Water Cycle (eds Jacobsen, S.D. \& van der Lee, S) 95-111 (Geophys. Monogr. Ser. AGU, 2006).

17. Stixrude, L. \& Lithgow-Bertelloni, C. Geophysics of chemical heterogeneity in the mantle. Annu. Rev. Earth Planet. Sci. 40, 569-595 (2012).

18. Kawakatsu, H. \& Yoshioka, S. Metastable olivine wedge and deep dry cold slab beneath southwest Japan. Earth Planet. Sci. Lett. 303, 1-10 (2011).

19. Kubo, T., Kaneshima, S., Torii, Y. \& Yoshioka, S. Seismological and experimental constraints on metastable phase transformations and rheology of the Mariana slab. Earth Planet. Sci. Lett. 287, 12-23 (2009).

20. Obayashi, M., Sugioka, H., Yoshimitsu, J. \& Fukao, Y. High temperature anomalies oceanward of subducting slabs at the $410-\mathrm{km}$ discontinuity. Earth Planet. Sci. Lett. 243, 149-158 (2006).

21. Bagley, B., Courtier, A. M. \& Revenaugh, J. Melting in the deep upper mantle oceanward of the Honshu slab. Phys. Earth Planet. Inter. 175, 137-144 (2009).

22. Honda, S., Morishige, M. \& Orihashi, Y. Sinking hot anomaly trapped at the $410 \mathrm{~km}$ discontinuity near the Honshu subduction zone, Japan. Earth Planet. Sci. Lett. 261, 565-577 (2007).

23. Morishige, M., Honda, S. \& Yoshida, M. Possibility of hot anomaly in the sub-slab mantle as an origin of low seismic velocity anomaly under the subducting Pacific plate. Phys. Earth Planet. Inter. 183, 353-365 (2010).

24. Kawakatsu, H. et al. Seismic evidence for sharp lithosphere-asthenosphere boundaries of oceanic plates. Science 324, 499-502 (2009).

25. Hirano, N. Petit-spot volcanism: A new type of volcanic zone discovered near a trench. Geochem. J. 45, 157-167 (2011).

26. Song, T-R.A. \& Kawakatsu, H. Subduction of oceanic asthenosphere: Evidence from sub-slab seismic anisotropy. Geophys. Res. Lett. 39, L17301 (2012).

27. Hofmann, A. W. Mantle geochemistry: The message from oceanic volcanism. Nature 385, 219-229 (1998).

28. Machida, S., Hirano, N. \& Kimura, J. I. Evidence for recycled plate material in Pacific upper mantle unrelated to plumes. Geochim. Cosmochim. Acta 73, 3028-3037 (2009).

29. Korenaga, J. Mantle mixing and continental breakup magmatism. Earth Planet. Sci. Lett. 218, 463-473 (2004).

30. Pysklywec, R. N. \& Ishii, M. Time dependent subduction dynamics driven by the instability of stagnant slabs in the transition zone. Phys. Earth Planet. Inter. 149, 115-132 (2005).

31. James, D. E., Fouch, M. J., Carlson, R. W. \& Roth, J. B. Slab fragmentation, edge flow and the origin of the Yellowstone hotspot track. Earth Planet. Sci. Lett. 311, 124-135 (2011).

32. Liu, L. \& Stegman, D. R. Origin of Columbia River flood basalt controlled by propagating rupture of the Farallon slab. Nature 482, 386-390 (2012).

\section{Acknowledgements}

We thank all the people in the NECESSArray project for installing and servicing the seismic array. Discussions with H. Zou and A. Forte were helpful in preparing the manuscript. The NECESSArray project was supported by NSF and JSPS.

\section{Author contributions}

Y.T. conducted the S-wave tomography and three-dimensional waveform modelling; M.O. conducted the P-wave tomography; F.N. conducted the receiver-function analysis; S.P.G. took the lead in writing the manuscript. All of the authors contributed to the data acquisition and interpretation.

\section{Additional information}

Supplementary information is available in the online version of the paper. Reprints and permissions information is available online at www.nature.com/reprints. Correspondence and requests for materials should be addressed to F.N.

\section{Competing financial interests}

The authors declare no competing financial interests. 